\title{
RANCANG BANGUN SISTEM ADMINISTRASI KEPENDUDUKAN PADA KELURAHAN PENJALANG DENGAN MENGGUNAKAN METODE WEB ENGINEERING
}

\author{
Sasmita \\ Teknik Informatika, Sekolah Tinggi Teknologi Pagar Alam \\ Jalan Masik Siagim No 75 Simpang Mbacang Kec.Dempo Tengah Kota Pagar Alam Sumatera Selatan \\ 082375102919 \\ E-mail : sasmitha661@gmail.com
}

\begin{abstract}
Population administration system in natural urban fence crossing urban villages still manually, still using a big book so that the population data search is still less effective. The purpose of this research is to design and build a population administration system in crossing urban villages by using PHP programming and MySQL Database. The methodology used is Web Engineering (web engineering). The results to be achieved are the availability of supporting applications in the urban village of Pagaralam that can be obtained without being bound by time and space. With this application in the weaving village it is expected to be able to help deliver information quickly and make it easy to get information about the weaving village.
\end{abstract}

Keywords: Web, Kelurahan Penjalang,Web Engineering, PHP

\begin{abstract}
Abstrak
Sistem administrasi kependudukan pada kulurahan penjalang kota pagar alam masih secara manual, masih menggunakan buku besar sehingga pencarian data penduduk masih kurang efektif, Tujuan dari Penelitian ini adalah untuk merancang dan membangun sistem administrasi kependudukan pada kelurahan penjalang dengan menggunakan pemrograman PHP dan Database MySQL. Metodologi yang dipakai adalah Web Engineering ( rekayasa web). Hasil yang ingin dicapai adalah ketersediaan aplikasi pendukung pada kelurahan penjalang Kota Pagaralam yang dapat diperoleh tanpa terikat ruang dan waktu. Dengan adanya aplikasi ini pada kelurahan penjalang diharapkan dapat membantu penyampaian informasi yang cepat dan memudahkan mendapatkan informasi tentang kelurahan penjalang.
\end{abstract}

Kata kunci: Web, Kelurahan Penjalang,Web Engineering, PHP

\section{Pendahuluan}

Berkembangnya Ilmu Pengetahuan dan Teknologi pada saat ini serta penerapan Teknologi Komputer dalam setiap aspek kehidupan sudah dianggap sebagai suatu kebutuhan, hal ini terjadi karena penerapan Teknologi Komputer dirasakan bisa membuat sebuah pekerjaan menjadi lebih cepat dan mudah. Teknologi Informasi merupakan salah satu pemicu terjadinya perubahan pola pikir manusia untuk dapat memperoleh informasi secara cepat dan akurat.

Untuk mengelolah dan menghimpun data registrasi penduduk haruslah memiliki suatu sistem/program yang dapat menunjang tugasnya. Pengolahan data registrasi penduduk masih sulit dilakukan. pengolahan data penduduk masih terkendala di fasilitas, data yang didapatkan tidak lengkap.

Dari gambaran di atas, maka perlu adanya upaya untuk memanfaatkan potensi yang terkandung dalam masyarakat guna melanjutkan pelaksanaan pembangunan. Oleh karena itu peranan Teknologi
Komputer sangat diperlukan untuk membangun suatu sistem administrasi kependudukan.

Aplikasi pengolahan data penduduk secara komputerisasi merupakan salah satu aplikasi yang saat ini menjadi alat bantu yang sangat efesien dalam menyimpan, memanipulasi, menganalisis dan menampilkan informasi. Peranan penduduk baik sebagai subyek atau obyek pembangunan membawa konsekuensi perlunya pengamatan perkembangan karakteristik kependudukan secara berkala, sehingga perubahan atau dinamika yang terjadi dapat terekam secara berkesinambungan.

Upaya ini lebih lanjut dapat diimplementasikan pada penentuan kebijakan bidang kependudukan yang selanjutnya potensi ini dapat dimanfaatkan bagi kelangsungan pelaksanaan pembangunan baik dibidang ekonomi maupun sosial. Kemampuan penduduk sangat menentukan corak dan pola kehidupan masyarakat sehingga upaya pengamatan karakteristik kependudukan diperlukan untuk menghindari kepadatan penyebaran penduduk yang tidak merata. Untuk mengetahui jumlah penduduk secara tepat, 

kecamatan dan 35 kelurahan secara berkala sebuah kesatuan bahasa pemodelan untuk membangun melaksanakan kegiatan pendataan penduduk pada perangkat lunak yang menggunakan teknik setiap desa/kelurahan melalui Badan Pusat Statistik pemrograman berorientasi objek. UML muncu karena Kabupaten/Kota. adanya kebutuhan pemodelan visual untuk pemodelan

Kelurahan Penjalang yang terletak di kecamatan dan komunikasi mengenai sebuah sistem dengan Dempo Selatan juga ikut berperan aktif didalam menggunakan diagram dan teks-teks pendukung. [4] meningkatkan mutu pelayanan serta menyempurnakan data kependudukan secara berkala. Salah satunya 2.4 Pengertian Internet

dengan melakukan pengolahan data penduduk secara

Internet adalah komunikasi jaringan komunikasi komputerisasi, pengelolaan data dengan komputerisasi global yang menghubungkan seluruh komputer didunia tentunya akan memudahkan dalam penyampaian meskipun beberapa sistem operasi dan mesin. [5] informasi penduduk. Selain itu, dapat mempermudah para pengambil kebijakan untuk dapat menemukan, 2.5 Pengertian Website

menganalisa serta mengatasi masalah kependudukan website merupakan kumpulan halaman-halaman yang terdapat pada daerahnya secara cepat. yang digunakan untuk menampilkan informasi teks, Berdasarkan uraian dan latar belakang di atas, maka gambar diam atau gerak, animasi, suara, dan atau penulis tertarik untuk mengangkat judul "Rancang gabungan dari semuanya, baik yang bersifat statis Bangun Sistem Administrasi Kependudukan Pada maupun dinamis yang membentuk satu rangkaian Kelurahan Penjalang Menggunakan Pemrograman bangunan yang saling terkait, yang masing-masing Php". dihubungkan dengan jaringan-jaringan halaman[6]

\section{Tinjauan Pustaka}

\subsection{Sistem}

sistem adalah kumpulan dari sub-sub sistem baik

\subsection{Rancang Bangun} abstrak maupun fisik yang saling terintegrasi dan

Rancang merupakan serangkaian prosedur untuk berkolaborasi untuk mencapai suatu tujuan tertentu. [7] menerjemahkan hasil analisa dari sebuah sistem ke dalam bahasa pemrograman untuk mendepenelitiankan dengan detail bagaimana komponen-komponen sistem diimplementasikan. [1]

\subsection{Xampp}

Xampp merupakan paket PHP dan MySQL

Perancangan adalah kegiatan yang memiliki tool pembantu pengembangan aplikasi berbasis PHP tujuan untuk mendesain sistem baru yang dapat Xamp mengombinasikan beberapa paket perangkat menyelesaikan masalah-masalah yang dihadapi lunak berbeda ke dalam satu paket. Sampai Xampp perusahaan yang diperoleh dari pemilihan alternatif versi 1.7.3. [8]

sistem yang terbaik. Sedangkan pengertian bangun atau pembangunan sistem menurut Pressman adalah 2.8 PHP kegiatan menciptakan sistem baru maupun mengganti

PHP berasal dari kata "Hypertext Prepocessor", atau memperbaiki sistem yang telah ada baik secara yaitu bahasa pemrograman universal untuk penanganan keseluruhan maupun sebagian.). [2] pembuatan dan pengembangan sebuah situs web dan

Dengan demikian pengertian rancang bangun bisa digunakan bersamaan dengan HTML. [9] merupakan kegiatan menerjemahkan hasil analisa ke dalam bentuk paket perangkat lunak kemudian menciptakan sistem tersebut ataupun memperbaiki sistem yang sudah ada.

\subsection{Administrasi}

kegiatan yang berkenaan dengan penyelenggaraan kebijaksanaan untuk mencapai tujuan. Administrasi dalam arti sempit adalah kegiatan yang meliputi: catat-mencatat, surat-menyurat, pembukuan ringan, ketik-mengetik, agenda, dan sebagainya yang bersifat teknis ketatausahaan. Administrasi dalam arti luas adalah seluruh proses kerja sama antara dua orang atau lebih dalam mencapai tujuan dengan memanfaatkan sarana prasarana tertentu secara berdaya guna dan berhasil guna. [3]

\subsection{Unified Modelling Language (UML)}

\section{Metodologi Penelitian}

Metodologi adalah kesatuan metode-metode, prosedur-prosedur, konsep-konsep pekerjaan, aturanaturan yang digunakan oleh suatu ilmu pengetahuan, seni atau disiplin lainnya. Metodologi pengembangan sistem berarti metode-metode, prosedur-prosedur, konsep-konsep pekerjaan, aturan-aturan yang digunkan untuk mengembangkan suatu sistem informasi. [10]

\subsection{Metode Pengumpulan Data}

Dalam rangka pengumpulan data yang diperlukan dalam penulisan Penelitian Penulis menggunakan beberapa metode, diantaranya adalah :

\section{a. Metode Observasi}

Menurut Jogiyanto Metode observasi merupakan salah satu metode pengumpulan data/fakta dengan melakukan pengamatan 
secara langsung suatu kegiatan yang sedang dilakukan.

b. Metode Wawancara

Menurut Jogiyanto Metode Wawancara merupakan suatu teknik pengumpulan data/fakta yang penting dan banyak dilakukan dalam pengembangan sistem informasi untuk mengumpulkan data secara tatap muka langsung dengan orang yang diwawancarai.

\section{c. Metode Studi Pustaka}

Menurut Jogiyanto Studi kepustakaan adalah teknik pengumpulan data dengan mengadakan studi penelaahan terhadap buku-buku, literatur-literatur, catatancatatan, dan laporan-laporan yang ada hubungannya dengan masalah yang dipecahkan.

\subsection{Metode Pengembangan Sistem}

Menurut Roger,S Presman Metode pengembangan sistem yang digunakan dalam penulisan penelitian ini adalah metode web engineering dengan tahapan sebagai berikut :

Metode web engineering terdapat 5 (lima) tahapan untuk dapat mengembangkan suatu perangkat lunak seperti gambar dibawah ini :

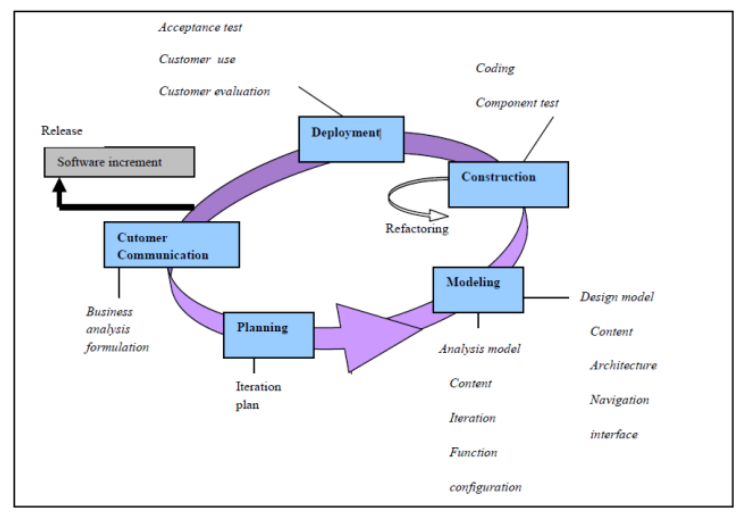

Gambar 1. Tahapan-tahapan Proses Web Engineering

\subsection{Analisa Rekayasa Web}

\section{Sistem Yang Berjalan}

Saat ini penduduk kelurahan Penjalang sangat sulit mencari informasi yang terdapat pada kelurahan, dan juga kesulitan dalam mendapatkan informasiinformasi tentang data penduduk. Untuk itu dibutuhkan suatu sistem yang dapat mengatasi masalah tersebut, dan untuk menggambarkan masalah tersebut dibuat suatu model yang berorientasi objek, bagaimana proses sistem yang sebenarnya berlangsung.
Di dalam sistem yang berlangsung warga penjalang harus datang langsung ke kantor kelurahan untuk dapat mengetahui informasi tentang data penduduk.

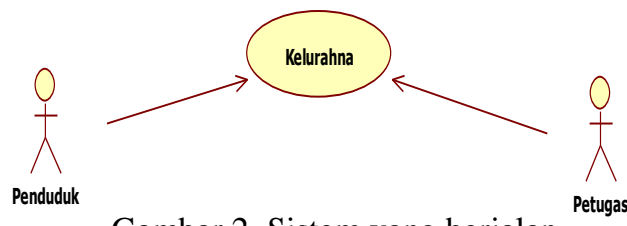

2. Sistem yang Diusulkan

Perancangan sistem perangkat lunak dengan model analisis dengan menggunaan Use Case serta dilanjutkan dengan model desain. Analisis digunakan untuk pemetaan awal mengenai prilaku yang diisyaratkan Perangkat Lunak kedalam elemen-elemen pemodelan. Untuk membantu perancangan dan melengkapi dokumentasi perancangan, digunakan STAR UML yang mendukung perancangan dengan basis UML. Dari sistem yang diusulkan ini diharapkan dapat membantu user (penduduk) dalam mengisi Formulir dengan mudah tanpa hambatan waktu, dimanapun dan kapanpun. User dapat browsing melalui internet dengan membuka website kelurahan Penjalang Kota Pagar Alam dan mengisi Formulir secara online tanpa harus datang ke kantor kelurahan.

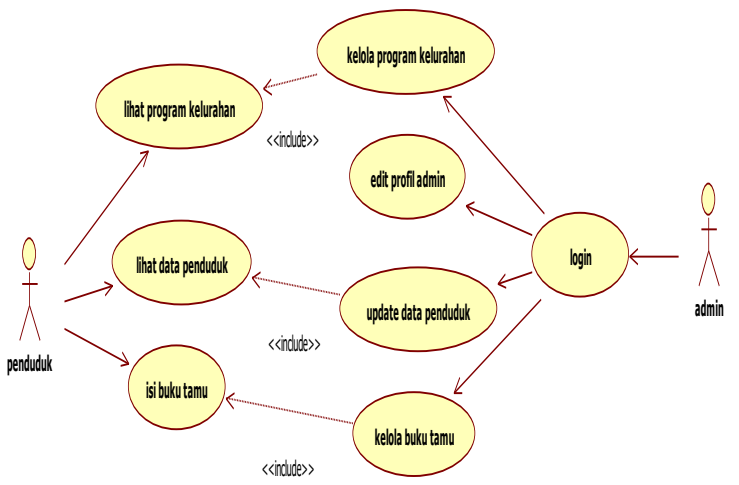

Gambar 3. Sistem yang diusulkan

\section{Activity Diagram Admin}

Activity Diagram Admin menggambarkan tahapan interaksi antara admin ke dalam sistem dimana admin dapat melakukan login ke dalam sistem Website Kelurahan Penjalang Pagaralam, maka sistem akan melakukan cek validasi data yang dimasukan ke dalam sistem Website Kelurahan 
Penjalang Pagaralam, apabila data valid maka keluarahan, visi misi keluarahan dan buku tamu. Menu admin dapat melakukan insert seperti tambah, ubah, login terdiri dari admin dan lurah, pengumumam dan hapus dan edit profil kemudian akan disimpan pertanyaan pengunjung tentang layanan dan program sebagai data baru oleh sistem, lalu admin dapat kelurahan.

melanjutkan aktifitasnya.

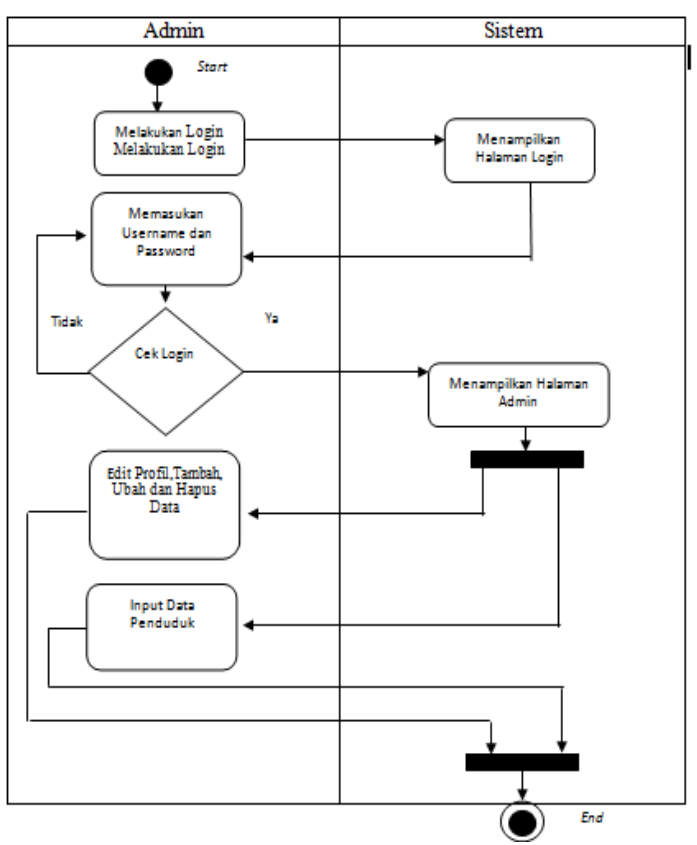

Gambar 4. Activity Diagram Admin

4. Activity Diagram Penduduk

Activity Diagram penduduk menggambarkan tahapan interaksi antara penduduk ke dalam sistem dimana penduduk langsung masuk ke dalam sistem Website Kelurahan Penjalang Pagaralam, maka penduduk dapat melakukan pengecekan data penduduk, lihat profil, mengisi buku tamu, lihat informasi kelurahan penjalang kemudian

\begin{tabular}{|l|l|}
\hline PENDUDUK & SISTEM \\
\hline & \\
\hline & \\
\hline & \\
\hline
\end{tabular}

Gambar 5. Activity Diagram Penduduk

\subsection{Rancanagan Interface}

\section{Rancangan Halaman Utama}

Halaman utama merupakan halaman awal yang ditampilkan pada saat pengunjung baik admin maupun user membuka website Kelurahan penjalang. Halaman ini memuat ucapan selamat datang di kelurahan penjalang, menu pilihan yang terdiri dari home, profil
Perancangan Menu Utama dan Menu Login, rancangan ini dibuat agar penampilan program ini lebih baik menarik selintas program dapat Dilihat gambar berikut ini :

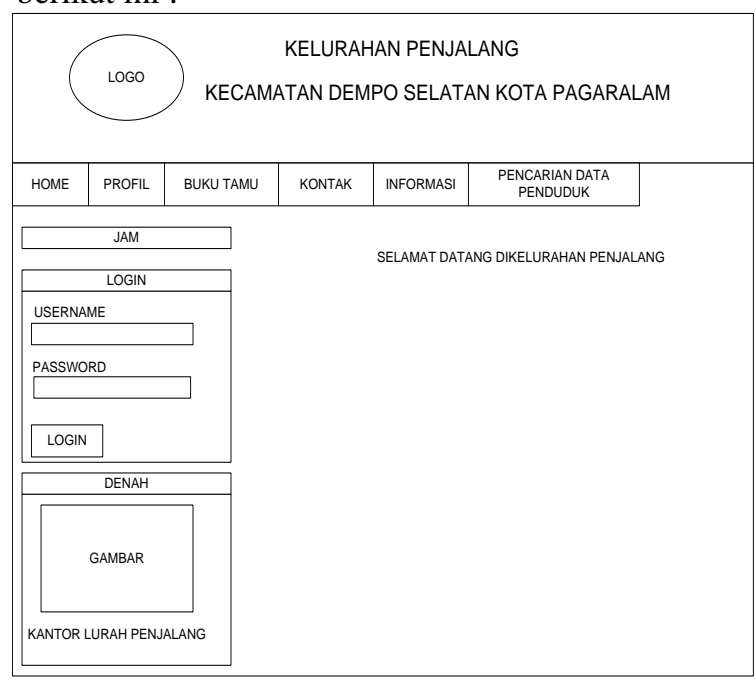

Gambar 6. Rancangan Halaman Utama

2. Rancangan Halaman Input Penduduk

Rancangan halaman input penduduk berada dimenu input yang ada dihalaman admin, guna untuk menambahkan data penduduk yang ada dikelurahan penjalang kecamatan dempo selatan . Rancangan halaman input penduduk dapat kita lihat seperti gambar dibawah ini

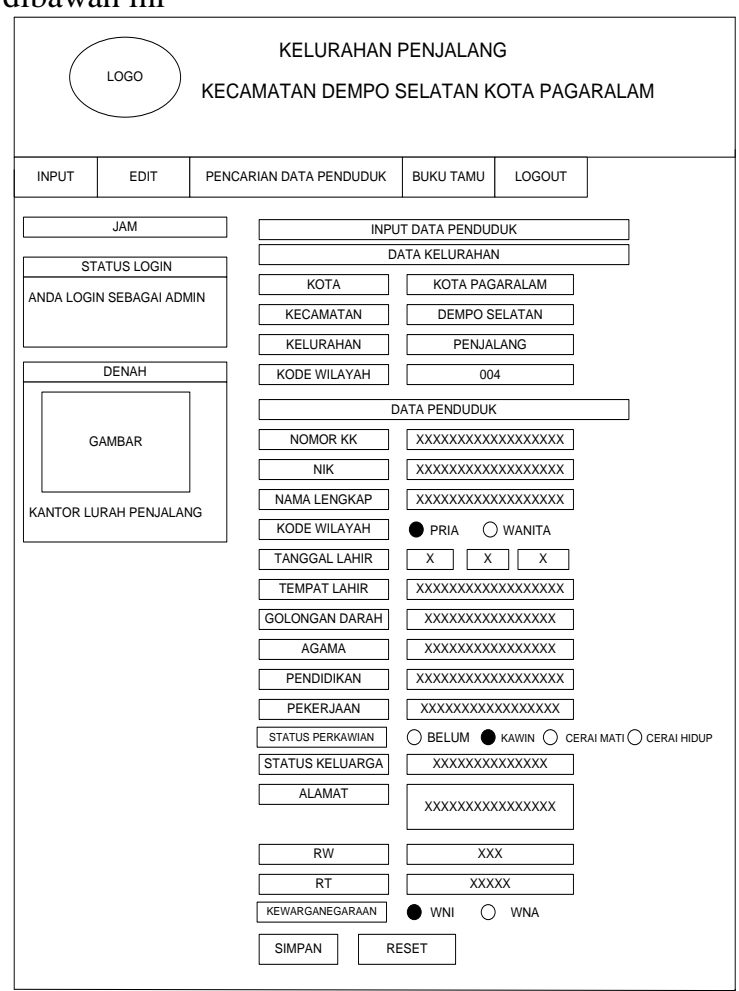

Gambar 7. Rancangan Halaman Input Penduduk 


\section{Hasil dan Pembahasan}

\subsection{Hasil}

Implementasi sistem adalah langkah-langkah atau prosedur-prosedur yang dilakukan dalam menyelesaikan desain sistem yang telah disetujui, untuk menguji, menginstal dan memulai sistem baru atau sistem yang diperbaiki untuk menggantikan sistem yang lama.

Implementasi yang telah sesuai harus diuji coba sehingga dapat diketahui kehandalan dan sistem yang ada telah sesuai dengan apa yang diinginkan. Tujuan implementasi sistem ini adalah :

1. Menyelesaikan desain sistem yang ada dalam dokumen desain sistem yang disetujui, menyusun dokumen baru atau dokumen-dokumen yang diperbaiki.

2. Menulis, menguji dan mendokumentasikan program-program dan prosedur-prosedur yang diperbaiki oleh desain sistem yang disetujui.

3. Memastikan bahwa user dapat mengoperasikan sistem yang baru

4. Memperhitungkan bahwa sistem memenuhi permintaan user yaitu dengan menguji sistem secara menyeluruh dan Memastikan bahwa konversi sistem yang baru berjalan secara benar yaitu dengan merencanakan, mengontrol dan melakukan instalasi sistem baru secara benar.

\subsection{Tampilan Website}

Pada Website Kelurahan Penjalang Kecamatan Dempo Selatan Kota Pagar Alam memiliki beberapa halaman, yang mana tipe halamannya masing-masing memiliki link, yang tiap isi halaman web menunjukkan setiap informasi yang berbeda-beda.

\subsubsection{Halaman Utama}

Halaman utama merupakan halaman awal yang ditampilkan pada saat pengunjung baik admin maupun user membuka website Kelurahan penjalang. Halaman ini memuat ucapan selamat datang di kelurahan penjalang, menu pilihan yang terdiri dari home, profil keluarahan, visi misi keluarahan dan buku tamu. Menu login terdiri dari admin dan lurah, pengumumam dan pertanyaan pengunjung tentang layanan dan program kelurahan.

Menu Utama dan Menu Login, halaman ini dibuat agar penampilan program ini lebih baik menarik selintas program dapat Dilihat gambar berikut ini :

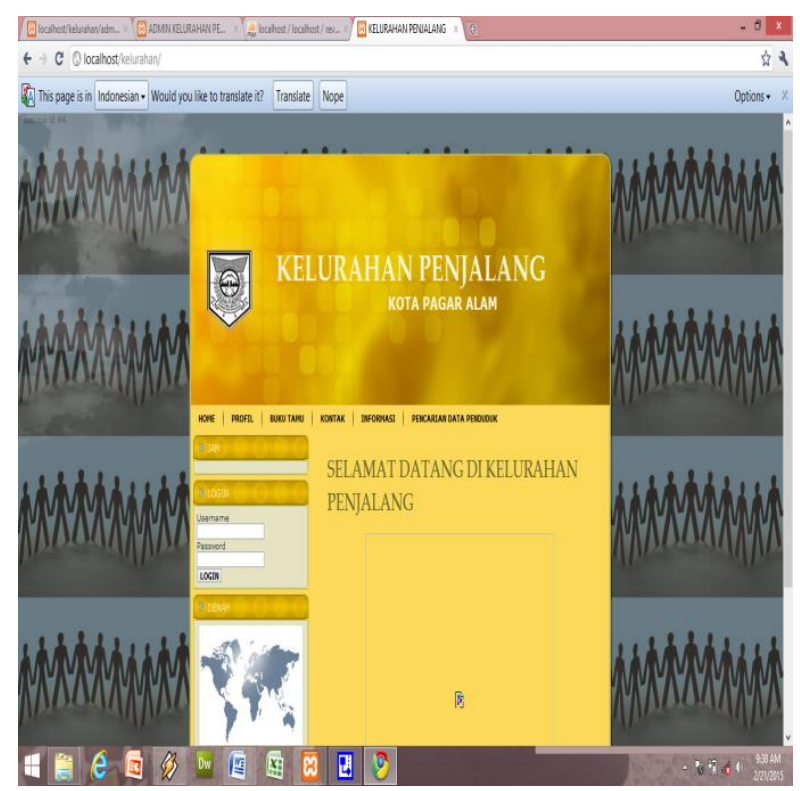

Gambar 8. Halaman utama

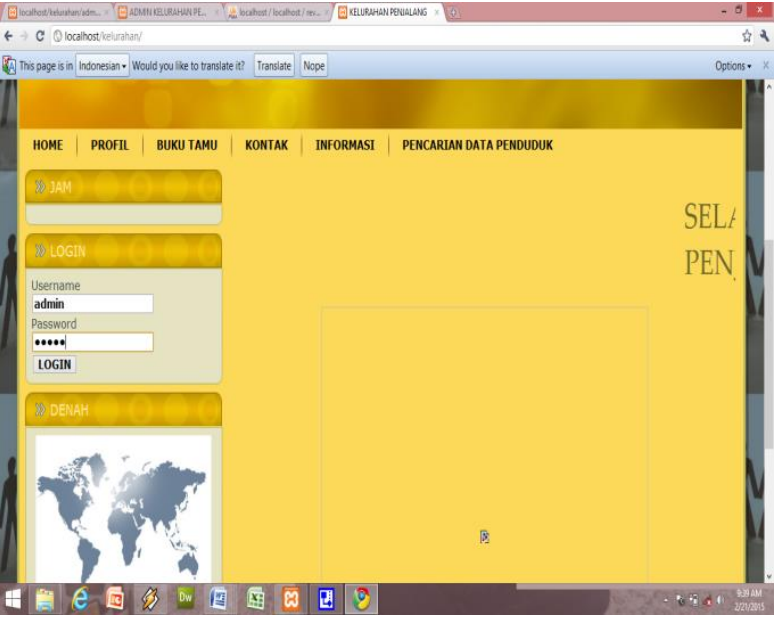

Gambar 9. Halaman Login

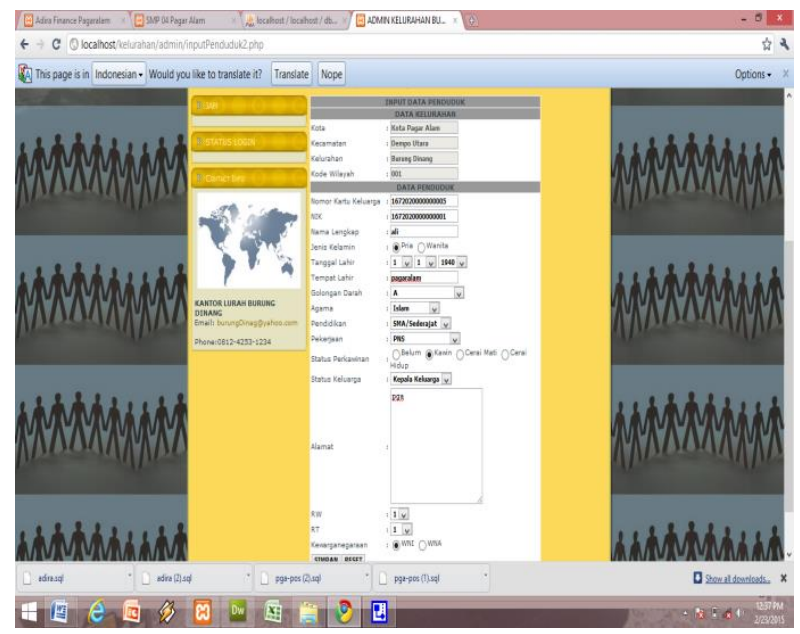

Gambar 10. Halaman Input Penduduk 


\section{Kesimpulan \\ 5.1 simpulan}

Adapun simpulan yang didapatkan pada penelitian ini menghasilkan Sistem Administrasi Kependudukan Pada Kelurahan Penjalang Dengan Menggunakan Metode Web Engineering yang dapat memudahkan pengolahan data penduduk dan

\subsection{Saran} dalam penyampaian informasi penduduk.

1. Hendaknya dalam penerapan sistem yang baru perlu terlebih dahulu diadakan penyesuaian dengan sistem yang ada atau sistem yang sedang berjalan.

2. Perlu adanya perawatan sistem agar dapat berjalan dengan baik dan selalu mengikti perkembangan teknologi.

\section{Daftar Rujukan}

[1] Roger,S Presman.2015. Rekaya Perangkat Lunak : Pendekatan Praktisi Buku I. Andi Yogyakarta

[2] Ladjamudin,Al-bahra Bin. 2013. Analisis dan Desain Sistem Informasi. Graha Ilmu Yogyakarta

[3] Dewi, Ira Chrisyanti. 2011. Pengantar Ilmu Administrasi. PT Prestasi Pustakaraya Jakarta

[4] Rosa,A,S dan M.Shalahudin. 2013. Rekayasa Perangkat Lunak. Informatika Bandung

[5] Ahmadi dan Hermawan. 2013. E-Busines \& ECommerce. Andi Yogyakarta

[6] Bekti,bintu Humairah. 2015. Mahir Membuat Website dengan Adobe Dreamweaver CS6,CSS dan JQuery. Andi Yogyakarta

[7] Rohmat Taufiq.2013. Sistem Informasi Manajemen Konsep Dasar, Analisis dan Metode Pengembangan. Graha Ilmu Yogyakarta

[8] Riyanto. 2016. Membuat Aplikasi Apotek integrasi Barcode Scanner Dengan PHP \& MYSQL. Gava Media Yogyakarta

[9] Mundzir MF. 2014. PHP Tutorial Book For Beginner. NOTEBOOK Yogyakarta

[10] Jogiyanto,H.2013.Metodologi Penelitian Bisnis Salah kaprah dan pengalaman-pengalaman Edisi Keenam. BPFE Yogyakarta 